\title{
Psychosocial support for children
}

\author{
Alison Clarke \\ Sherry Hutchinson \\ Population Council \\ Ellen Weiss \\ Population Council
}

Follow this and additional works at: https://knowledgecommons.popcouncil.org/departments_sbsr-hiv How does access to this work benefit you? Let us know!

\section{Recommended Citation}

"Psychosocial support for children," The Horizons Report, June. Washington, DC: Population Council, 2005. 


\section{$\mathrm{H}$

Children participate in an outdoor activity as part of their 10-day residential program at Salvation Army Masiye Camp in Zimbabwe.

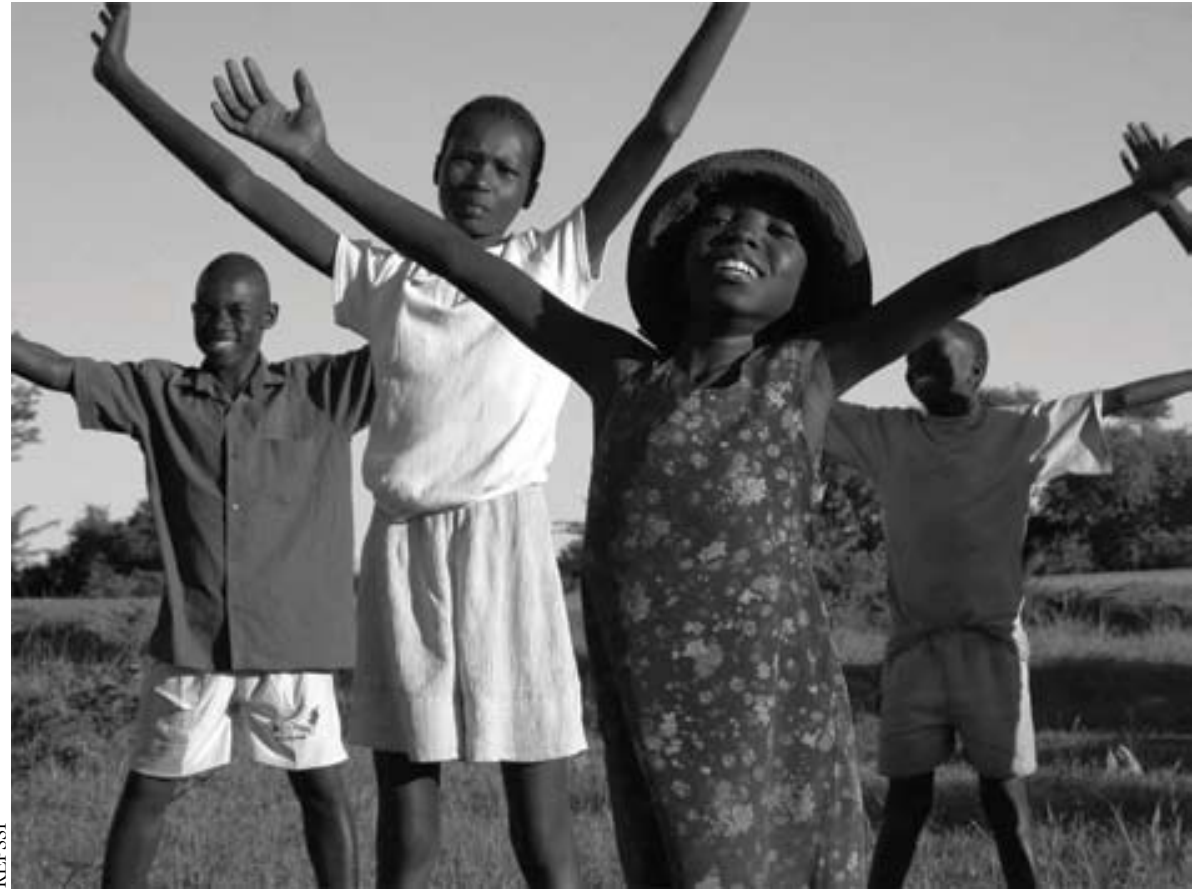

Providing Psychosocial Support to AIDS-AFfected Children

\section{Operations research informs programs in Zimbabwe and Rwanda}

In Matopos National Park, Zimbabwe, the sun sets gracefully, casting shadows over massive granite rock formations as white rhinos lumber toward their water holes. Not far away, the calls of children can be heard as they finish their afternoon activities and prepare for dinner. The voices of camp counselors rise above those of the children, directing them toward their next pursuit.

But the activities that these children are experiencing during their ten days together at Salvation Army Masiye Camp serve a greater purpose than fun and games. The youth have been chosen by their communities to participate in this residential, faith-based program in Matabeleland Province because their lives have been profoundly affected by HIV/AIDS.

At the same time, 30 miles away in downtown Bulawayo, other children are engaged in an energetic soccer game while their peers work on art projects in a room nearby. These children too are participating in structured programs, called Kids' Clubs, designed to help the ever-growing population of orphans and vulnerable children in the country.

Masiye Camp and the Kids' Clubs are examples of a growing number of programs in Africa and elsewhere that focus on the psychological and social needs of AIDS-affected children. Given the traumatic effects of grief, loss, and other hardships faced by these children, there
Psychosocial Support for Children

\section{Inside:}

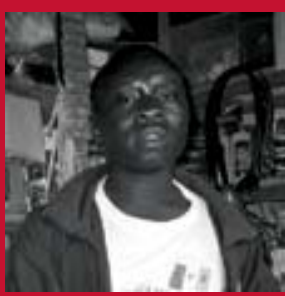

Youth-headed Households Page 6

Studies in Brief Page 9
The Population Council implements the Horizons Program in collaboration with the International Center for Research on Women, the International HIV/ AIDS Alliance, the Program for Appropriate Technology in Health, Tulane University, Family Health International, and Johns Hopkins University. 
is increasing recognition of the importance of programs to help them strengthen their social and emotional support systems. This issue of Horizons Report describes findings from operations research in Zimbabwe and Rwanda (see page 6) that examines the psychosocial well-being of orphans and vulnerable children and ways to increase their ability to adapt and cope in the face of adversity.

In these studies, a person's psychosocial wellbeing refers to his/her emotional and mental state (psycho-) and his/her network of human relationships and connections (-social). Good psychosocial well-being is when one's mental/emotional state and social relationships are predominantly positive and healthy. Lack of psychosocial well-being or psychosocial distress is when these are mostly negative or unhealthy.

\section{The Zimbabwe Study}

Youth affected by AIDS typically face a wide range of stressful events and circumstances, including the loss of caregivers, the burden of adult-like responsibilities, and social isolation. Yet little is known about whether programs such as Masiye Camp and the Kids' Clubs, which aim to improve psychosocial well-being directly through counseling, spiritual support, group recreation, and peer-to-peer support, do indeed help the youth they target.

In response, researchers from the Regional Psychosocial Support Initiative (REPSSI), the STRIVE Program of Catholic Relief Services, and the Horizons Program collaborated on an exploratory study in southern Zimbabwe. The study sought to develop a better understanding of psychosocial well-being among vulnerable youth and how to measure it, and explore the effects of participation in psychosocial support programs.

The Zimbabwe study began in June 2003 with formative research, which included in-depth interviews and focus groups. Informants included youth and adults working with youth, such as teachers, NGO staff, pastors, and counselors. Researchers then used the qualitative findings and select items from standardized surveys to draft a questionnaire to learn more about the psychosocial well-being and psychosocial distress of vulnerable youth. The survey tool was refined based on pretesting and on feedback from local youth and international experts.
Local interviewers administered the questionnaire to a sample of vulnerable youth, aged 14 to 20. The study focused on this age group because of the presence of programs for them in the study area and because they face unique responsibilities and challenges, including caring for younger children and sick adults. The sample included youth who had and had not participated in community psychosocial programs, such as Masiye Camp and the Kids' Clubs.

\section{Life Circumstances}

A total of 1,258 youth were interviewed, 604 males and 654 females. All were deemed vulnerable by their communities because they had been

\section{Participation in psychosocial support programs is associated with greater self confidence, especially among males.}

affected by HIV/AIDS and/or other factors such as severe poverty. The average age of respondents was 15.9 years. The vast majority were enrolled in school, but two-thirds had not completed the expected level of schooling for their age. Only about a third of respondents had both parents living; the rest were orphans, mostly paternal orphans (father deceased) or double orphans (both parents deceased).

The study yielded mixed results with respect to social support for youth and their feeling of social connectedness. Peer relationships are an important source of social support and coping, as over 90 percent of youth said that they enjoy time spent with friends. However, while 88 percent of youth reported seeking help from an adult in times of difficulty, only about half feel "very well" supported by adults in their lives. Orphans in particular reported not having any adults to talk to about problems, and 22 percent of those living with guardians have been made to feel unwelcome. Overall, orphans scored lower on the social support measures than did non-orphans.

The researchers developed a trauma index to measure the level of potentially traumatizing events experienced by each respondent. Among the entire study sample, most respondents had experienced multiple traumas. These included the 
death of loved ones, illness in the family, stigma and discrimination, loss of land or possessions, and rejection in times of need. Females had significantly higher trauma scores than males.

\section{Distress and Resilience}

Youth reported high levels of psychosocial distress. For example, 76 percent felt guilty, 70 percent felt worried or stressed, 63 percent felt sad, and 61 percent felt overwhelmed by problems some or most of the time in the last month. Headaches, nightmares, trouble concentrating, and fatigue were commonly reported signs of emotional distress. Females were significantly more likely to report signs of psychosocial distress. As expected, the researchers found that high exposure to trauma was associated with high levels of psychosocial distress, such as anxiety and depression.

Despite adverse circumstances, many respondents showed signs of positive psychosocial wellbeing and resilence. More than three-fourths felt self-confident, hopeful about the future, and that they could do things to help themselves in the last month.

"These findings suggest that signs of positive and negative psychosocial well-being are not mutually exclusive," said Linda Dube of REPSSI, one of the study's principal investigators. "Although emotional distress is widespread, there is a considerable level of resilence in this vulnerable group of youth.”

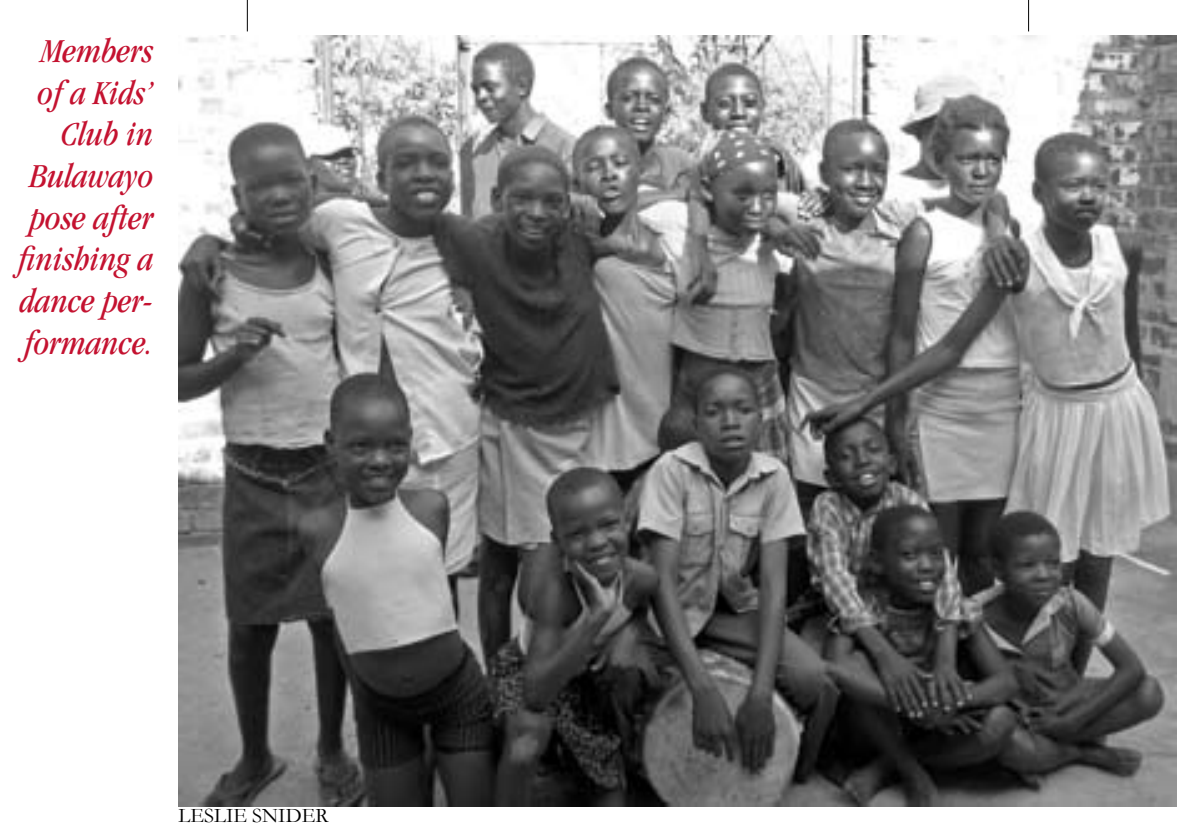

\section{Differences Between Groups}

All youth in the study were in one of four study groups. The first group consisted of youth who participated in community-based psychosocial support programs, such as the Kids' Clubs, which offer a variety of structured, specialized activities to foster support on an ongoing basis.

Youth who attended Masiye Camp's residential, 10-day program, which aims to build self-esteem, trust, and skills in communication and conflict resolution, made up the second group.

The third group consisted of youth who attended Masiye Camp as campers and then became either a Masiye Camp counselor or a youth leader in a community psychosocial support program.

The fourth group, or comparison group, was made up of youth who had never participated in any formal psychosocial support program, but were identified as being vulnerable by community members consulted by the study investigators. (The youth in the comparison group received psychosocial support either from community programs or the Masiye Camp after the study.)

The researchers did not collect data on the youth before and after they participated in the interventions, nor were participants randomly assigned to study groups. Therefore, they cannot prove that the interventions are responsible for a particular outcome. However, using multiple regression analysis, the researchers examined differences in select psychosocial well-being variables (e.g., self-confidence) and psychosocial distress variables (e.g., sadness) between the intervention groups and the comparison group.

When comparing the intervention groups to the comparison group, all three interventions are associated with greater self-confidence, especially among males. For example, 96 percent of males in the counselor/leader group reported feelings of self-confidence compared to 77 percent of those in the comparison group, a statistically significant difference. Similarly, males in the community psychosocial program group were significantly more likely to report feeling self-confident in the last month than comparison group peers (85 vs. 77 percent). 
"This is an interesting finding and reflects the aims of the interventions," said Laelia Gilborn, formerly of Horizons/Population Council, a principal investigator. "But more rigorous research is needed to find out whether the programs attracted more self-confident youth or whether the programs are responsible for increasing self-confidence."

The study also found positive trends for ability to cope and ability to help oneself, depending on the intervention, although these associations are not statistically significant. For example, a greater proportion of males and females in the Masiye Camp and the counselor/leader group felt that they could cope with difficulties in their lives compared to the comparison group.

Surprisingly, respondents in each of the three intervention groups reported more psychosocial distress than comparison group youth.

For example, a greater proportion of males and females in the counselor/leader group reported being sad and overwhelmed than youth in the comparison group. In addition, a greater proportion of females in the counselor/leader group reported crying, hopelessness about the future, and disinterest in life than females in the comparison group. Although none of these differences is statistically significant there is a pattern, whereby counselors/leaders, particularly females, may experience greater emotional distress.

This unexpected finding - a greater proportion of youth in the intervention groups exhibit signs of psychosocial distress - stimulated extensive discussion among the researchers and program implementers.

One possible explanation is that the programs help vulnerable youth become more articulate and open about their feelings of distress.

"Attending the Masiye Camp and becoming a leader may help youth become emotionally literate, which allows them to better express emotions," said Leslie Snider of Tulane University, another study investigator. "If so, psychosocial support programs need to ensure that activities do not simply bring out emotions, but also help youth to cope with such feelings over time."

The additional responsibilities taken on by the leaders/counselors, such as mentoring and counseling younger children, could also contribute to their comparatively higher levels of distress.

\section{Program Implications}

Youth in this study confront many traumatic experiences that likely lead to emotional distress. This context represents a serious challenge for psychosocial support programs. The research

\section{Efforts to sensitize community members to the need children have for someone} to talk to are necessary.

suggests ways to strengthen these programs to both promote psychosocial well-being and reduce emotional distress.

The findings show that many youth, particularly orphans, perceive that they do not receive adequate guidance and support from adults. An important role for psychosocial support programs would then be to link youth with trusted adults. Increased efforts to sensitize community members and caregivers to the needs children have for someone to talk to about their feelings, relationships, and life decisions are necessary.

Programs also must better understand the grieving process in Zimbabwean youth, and, based on that understanding, help children cope with grief and distress over time, such as instituting or strengthening ongoing community-based followup. In addition, they also need to be sensitive to each child's particular needs, such as those who require more skilled support in grief resolution.

More time and attention must be focused on responding to the gender-specific, psychosocial needs of females, as they appear to be particularly vulnerable. Girls-only activities may be useful.

A final report on this study will be published in mid-2005. 8

This article was written by Alison Clarke, in conjunction with members of the research team, which includes Laelia Gilborn, formerly of Horizons/Population Council; Linda Dube, Jonathan Brakarsh, Mark Kluckow, and Tricia Smith of REPSSI; Leslie Snider of REPSSI and Tulane University; Kyle Jemison of CRS/STRIVE; and Louis Apicella of Horizons/Population Council.

For more information about this study, contact Laelia Gilborn (laelia_gilborn@hotmail.com) or Linda Dube (Idube@repssi.org). 


\section{UTILIZING THE RESEARCH \\ Zimbabwe groups discuss and apply the findings}

7 he findings from this study have

1 been discussed at local dissemination

meetings and have led to a review of program approaches and incorporation of new strategies. For example, the Kids' Clubs have increased the participation of community leaders and volunteers in their program activities. This was done so that community members would better understand the importance of play and other activities in helping children socially and psychologically, and to enlist them in helping to provide ongoing care and support to children in their community.
Concerned about the levels of psychosocial distress and grief among the campers, particularly among females, Salvation Army Masiye Camp has adapted its activities to better engage children in a narrative, reflective process that focuses not only on difficulties in the past but on plans for the future. As part of this process, the children now create and discuss a Tree of Life (see below) that illustrates their personal strengths, joys, and tribulations. This activity has been added by Masiye Camp to better prepare youth for a more intense follow-up session on loss and bereavement.

\section{Tree of Life}

This activity helps participants understand themselves better on a psychosocial level.

\section{Instructions}

Each participant is given a piece of paper and colored markers. In a specific given time, they each draw a tree that will represent who they are. The following tree parts represent the

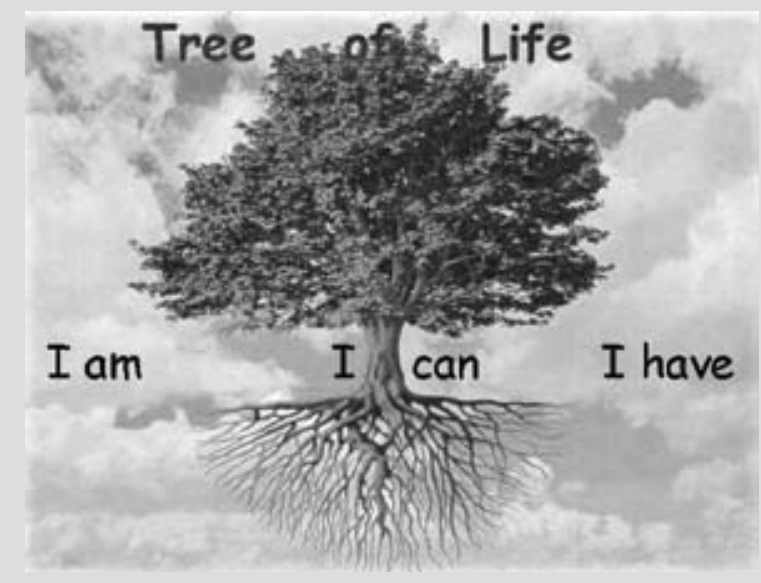
different aspects of each person's life:

The soil: Place of origin

The roots: Ancestry, and cultural, ethnic, or tribal background

The trunk: The people, places, and events that influenced one's life when growing up

Main branches: The people, places, and events that influence one's life today

Fruits: Definition of what makes one's life today; also defines one's psychological principles

Bugs: Personal characteristics, places, and/or events that contribute to downfalls in one's life today; i.e. problems and challenges that one faces today

Leaves on the ground: Losses or traumas one has experienced or suffered in life

It is recommended that each participant share their completed Tree of Life with the rest of the group. Comments and questions can be asked for encouragement and clarification. 


\section{On Their Own}

\section{Strengthening youth-headed households in Rwanda}

All over the world AIDSaffected children face innumerable challenges with respect to their physical, economic, and emotional well-being. But in Rwanda, the 1994 genocide has compounded the effects of the ongoing AIDS epidemic, resulting in one of the world's highest percentages of orphans among children 17 years or younger (17 percent) and large numbers of youth-headed households ${ }^{1}$. Many of these young people are essentially on their own, left behind by parents and other caregivers, stigmatized by war or disease, and neglected by extended families, communities, and formal

\section{structures.}

Traditionally, programs for orphans and vulnerable children in Rwanda and elsewhere have focused on providing material assistance, such as school fees, food, and health care. But program managers are increasingly recognizing the importance of social and psychological services to foster the healthy emotional and physical development of these young people.

In Rwanda, a World Vision program has provided support since 2000 to youth-headed households, a distinct subset of orphaned children, to meet their nutritional, shelter, educational, and health care needs. However, information gathered from children and youth in these households revealed their ongoing sense of isolation, loneliness, and exposure to maltreatment. World Vision
Rwanda (WVR) realized that the project's beneficiaries had other needs that could not be met by material support alone. They also recognized the importance of research to help design an intervention to better meet the needs of their beneficiaries and to assess its impact.

In response, WVR teamed up with Tulane University School of Public Health, the Rwanda School of Public Health, and the Horizons Program to improve the psychosocial well-being of youth-headed households in four districts in Gikongoro province through a community mentorship program.

As part of the operations research process to design and evaluate the mentorship program, the researchers conducted focus groups with youth and adults in late 2003. In March 2004, they administered a baseline survey to 692 youth heads of households who were WVR program beneficiaries.

The survey sample included an almost equal number of males and females and most were between the ages of 19 and 24 (range: 12 to 24 years). For 70 percent of respondents, both parents are deceased. The remainder have been abandoned or do not know their parent's whereabouts. Nearly a third care for three or more children, with females more likely than males to care for several children. 


\section{Multiple Needs}

Findings from the baseline research show that the needs of respondents are vast and complex. Although most of the sample have been receiving services from WVR for several years, indicating a considerable length of time as head of their household, they continue to face significant challenges to meeting their basic needs and safeguarding their health and emotional well-being.

Only about a fourth of the school-age respondents are in school. Barriers to attendance include school expenses and responsibilities at home. More than half of respondents do not possess a pair of shoes and 31 percent of households do not have a latrine. Nearly a fourth of respondents consider themselves to be in poor health and nearly half of these youth report having a serious illness at the time of the survey.

To provide for themselves and their families, the vast majority depend on farming and selling produce. Very few depend on parents' savings or assistance from friends or relatives. Because of limited resources, many consistently face a shortage of food, with 44 percent indicating that they eat only once a day. Among respondents with younger youth at home, more than half had gone without food sometime within the week preceding the survey so that the others in the household would have enough to eat. Only 54 percent feel they are sufficiently providing for the needs of their family.

\section{Psychological and Social Impacts}

Taking on the role as head of household has had significant psychological and social impacts on these young people. Researchers found that more than 80 percent of respondents had felt depressed or desperate since the loss of or abandonment by their parent(s). Moreover, they are still greatly affected by the loss, which, for many, has reduced their confidence in other people (64 percent) and contributed to their feeling that life is meaningless (44 percent).

Many youth feel unsupported by members of their extended family. Although 82 percent report contact with their relatives and a majority say that they see them at least once a week, only 36 percent trust their relatives to look out for their best interests. In fact, more than twice as many have confidence in the willingness of their neighbors to help them (57 percent) than their extended family (25 percent). The vast majority ( 85 percent) feel that only World Vision staff care about them.

Most respondents feel isolated from the community, think that people speak badly about them, and feel that others would rather hurt them than help them. Females had less confidence in their neighbors to help them and less trust in the community than males.

Youth perceive a lack of community support for various reasons. Many cited the war, noting that since then, people no longer help one another. Others suspect that they are not liked because of their poverty or because the community had ill feelings about their parents. Eighty-seven percent of respondents think that the community feels it is World Vision's responsibility to take care of the children's needs. Also, over three-quarters believe the community is jealous of the services they are granted as orphans.

Lacking adult protection, study investigators found that the respondents and their households are extremely vulnerable to mistreatment. Youth reported instances of abuse, from sexual and physical abuse to exploitation. Over half said someone intentionally harmed their property, and more than a third reported that someone tried to steal their land or property. More than a fourth of respondents (males especially) reported having been beaten. Females are vulnerable to sexual coercion, with nearly one in 10 reporting being forced to have sex. Given fear or embarrassment around sexual abuse and rape, it is likely that this number is actually higher. In addition, 10 percent of 
females said they submitted to unwanted sex in hopes of obtaining support for themselves and/ or their families. A smaller percentage of males reported being forced to have sex (1 percent) or having unwanted sex in hopes that the person would take care of them and their siblings (6 percent).

\section{Mentorship Model}

The findings from the baseline research support the basic premise of the mentorship programthat these young people need someone to talk to, to protect and defend them, and most of all, to let them know that the community cares about them.

"This love, support, and guidance cannot come just from an NGO; it must come from neighbors, family, and friends who comprise the network of social connections in their lives," said Leslie Snider of Tulane University, one of the study's principal investigators.

The mentorship program involving 156 adult volunteers began in October 2004 with 442 of the 692 study households. The mentor volunteers have been carefully recruited and trained, and receive ongoing support to develop a stable, caring relationship with children and youth through regular home visits. The volunteers help build their life skills; provide guidance, attention, and encouragement; and help to ensure their health and safety. Importantly, they also build a caring and trusting relationship with youth that, over time, will hopefully yield positive benefits for their health and psychosocial development.

While spending one to two hours with the youth during their visits, the mentors engage them in conversation, help solve problems, and evaluate their physical and emotional needs. The volunteers record their observations on a simple pictorial monitoring form that they discuss at volunteer group meetings and submit to WVR to help them monitor the household needs and prioritize the distribution of WVR resources.

\section{Encouraging Results}

Initial results from the first three months appear promising; averaging three visits a month, the mentors made more than 4,000 visits in total. Although some adult volunteers initially encountered resistance from the youth, many of these mentors reported that after a few visits, the youth opened up and now look forward to their visits.
The adult volunteers appear to be an important asset to the children, especially as a mediator within the home and in the community. The adults have helped solve issues between siblings, such as

Initial results from the first three months appear promising; averaging three visits a month, the mentors made more than 4,000 visits.

selling resources to buy non-essential items and physical abuse by an older sibling. One mentor helped a youth access legal services to get payment for a goat that had been stolen by someone in the community.

Working with WVR, the mentors also have discussed the baseline research findings at four community meetings in order to increase awareness about the problems faced by the youth and children they are mentoring and to engage community members in their care and support.

After the first year of program implementation, the survey will be repeated with the same youth to assess the impact of the mentorship program on their psychosocial well-being, specifically their social connectedness, role functioning, psychological health, and general well-being. World Vision Rwanda will expand the program to all households after the second survey. Study results should be available mid-2006. $R$

${ }^{1}$ UNAIDS, UNICEF, and USAID. 2004. Children on the brink 2004: A joint report of new orphan estimates and a framework for action. New York: UNICEF

This article was written by Sherry Hutchinson, in conjunction with members of the study team, which includes Leslie Snider, Lisanne Brown, Neil Boris, and Tonya Thurman of Tulane University; Joseph Ntaganira of the Rwanda School of Public Health; and Kofi Hagan, Edward Kalisa, and Eleazer Nkunda of World Vision Rwanda.

For more information about this study, contact Leslie Snider (Isnider@tulane.edu) or Joseph Ntaganira (jntaganira@yahoo.com). 


\section{ETHICAL ISSUES IN PROGRAM DESIGN AND RESEARCH \\ Rwanda study tackles ethical dilemmas}

7 he project team working on the youth1 headed household intervention study in Rwanda very seriously considered the ethical issues involved in research and program development for vulnerable youth. A critical component was consulting with youth and community members on how best to conduct the research and design the program.

\section{Selection of Mentors}

As a result of community consultation, a very careful selection and monitoring process for mentors has been instituted. As part of the process, children recommend adults they trust to enter the pool of applicants, since they often already know who is helpful and who is exploitive. Then, WVR screens and interviews each applicant.

Based on recommendations from youth and adults, the mentors are not paid. By offering payment, they felt the program would attract people with the wrong motives. Instead, the volunteers are offered incentives, including recognition by the community for their efforts.

To monitor the mentoring process, WVR schedules visits to the household both with and without the mentor present. Youth can refuse their mentor at any time without giving a reason.

\section{Conducting the Research}

To ensure good ethical practice in all phases of conducting the research, the team has emphasized the following:

Privacy - Interviews with the youth heading the household are as private as possible-only siblings under age two can be present.

Confidentiality - The information obtained in interviews is not shared with
WVR, except to ensure the respondents' safety, and respondents are fully informed of this.

Informed consent - Respondents are fully informed that they can refuse to participate without any repercussions, including losing WVR services. As the youth participating in the program are living without adult care, the team felt they are able to give consent and that it is important for them to participate in decisions that affect their lives, such as taking part in the research.

Interviewer training - Interviewers have been extensively trained on sensitive and supportive interviewing techniques, including assuring youth they do not have to answer questions that upset them and they can terminate the interview at any time, and ending the interview themselves if youth are distraught. During training, the interviewers role played how to deal with various types of distress they might encounter in the field. They were also supervised in the field and given regular debriefing and support sessions to address their own emotions as a result of hearing sad stories from respondents.

Referral network - The project team anticipated the possibility of uncovering serious emotional distress, poverty, or other crises during the interview process, and set up a referral system for children and youth at risk prior to the start of the research. For example, households with serious problems related to basic needs (lacking adequate shelter, food, or with serious health needs) were referred to WVR for follow-up with the permission of the respondent. In cases of severe emotional distress, WVR linked those youth with mental health services previously identified in the community. 


\section{STUDIES IN BRIEF}

\section{KAMPALA, UGANDA}

\section{Study highlights ways to increase VCT uptake and satisfaction among youth}

$\mathrm{V}$ oluntary counseling and testing (VCT) programs stand out among HIV/AIDS interventions because of their dual role: Not only do they help clients adopt HIV-preventive behaviors, but they also identify people that need HIV care. Given that many of those newly infected with HIV are young people, VCT program managers and policymakers are increasingly recognizing the importance of encouraging youth to seek HIV counseling and testing and of modifying their services to meet youth's particular needs.

A Horizons study conducted in Uganda from 2001 to 2003 tested new strategies to increase VCT utilization and satisfaction among young people. The intervention study builds on earlier research conducted in Kenya and Uganda, which revealed that youth want information about HIV and AIDS, low-cost HIV testing, and friendly, confidential, and professional counseling ${ }^{1}$. Two facilities in Kampala, Uganda, the AIDS Information Center (AIC) and Naguru Teenage Information and Health Center (NTIHC), responded to these requests by reorienting their services to better serve youth.

AIC has provided stand-alone VCT services since 1990. Although AIC had served youth as well as adults, it did not target youth specifically. In 2001, AIC established a youth corner with a separate gate behind the regular adult clinic so youth could enter in privacy. AIC also reduced the HIV testing fee for youth.

Open since 1995, NTIHC is a drop-in center for youth that offers free reproductive health services, including family planning, pregnancy testing and counseling, and antenatal and postnatal care. In 2002, NTIHC began offering VCT two days per week and expanded its facility to provide waiting and counseling space for youth seeking VCT.
AIC developed a three-day training course for counselors at both sites on how to counsel youth seeking VCT. Specific issues addressed by the training included mental and emotional development in adolescence, how to discuss puberty with youth, and pressures in the environment that affect youth decision-making.

AIC and NTIHC informed young people about the new services by discussing VCT and the test locations on a popular radio call-in show, placing information in a well-established youth magazine, and distributing materials.

To evaluate these efforts, researchers from Makerere University and the Horizons Program conducted exit interviews with youth 14 to 21 years old who had sought services at AIC and NTIHC, in-depth interviews with some of these clients, and focus groups with tested and untested youth.

The study found that youth were highly satisfied with the new youth-oriented services. While overall satisfaction with VCT services at AIC was generally high before the intervention ( 79 percent), it increased after provider training and implementation of the youth corner ( 95 percent). There were also increases in the proportion of youth clients at AIC who indicated that the counselor took important steps as part of the VCT process such as praising the client for having the courage to come

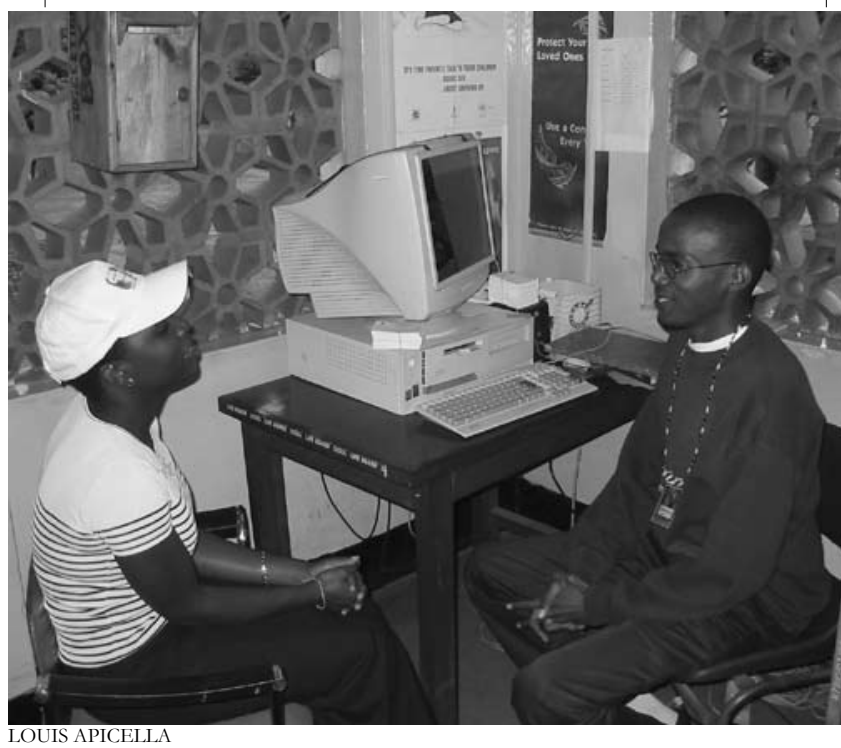

A peer counselor with a female client at the Naguru Teenage Information and Health Center in Kampala, Uganda. 
for services, clarifying information, correcting misconceptions, repeating important information, and responding to their concerns and worries.

Among NTIHC clients, satisfaction with services was also very high (93 percent) after VCT had been introduced.

When asked to name the three things they liked best about the services, the greatest number at both sites mentioned "friendly provider." A large majority also mentioned warm reception and provider professionalism.

"I was so worried because I had lost a lot of weight but I stopped worrying when I came to this place. The reception was so good. It was like life goes on and these people are very caring," said a male youth at AIC.

Almost all of the youth clients interviewed indicated that their counselor exhibited good counseling skills. This finding is particularly important given that NTIHC used peer counselors (AIC used professional adult counselors). In addition, all of the youth interviewed from both clinics reported that the professional and peer counselors were nonjudgmental, listened attentively, and encouraged the client to speak. Steps that counselors at both sites did not take as consistently with youth clients were making referrals for treatment, further counseling, or care services.

But, peer counselors faced particular challenges in their counseling roles. For example, some reported that clients occasionally questioned their authority and expertise. In addition, young counselors were more likely to feel isolated and less likely to feel confident about their skills.

More females than males have used the newly structured VCT services at both sites. Interestingly, AIC is attracting more young women who pay for the service themselves rather than rely on a partner to pay for VCT. This change may be due to the reduction in HIV testing fees, enabling more females to pay for VCT themselves.

The new services received positive reviews, but unfortunately both AIC and NTIHC could not handle all the young clients who came in response to the promotional activities and word of mouth.

"The response to the new services has been overwhelming," says Ann McCauley, formerly of Horizons/International Center for Research on Women, one of the study's principal investigators. "Young people were eager to talk to a health coun- selor about HIV, and the counselors were gratified because some youth sent thank you notes and referred their friends to the counselors by name."

To avoid disappointing youth, AIC booked only the number of youth they could handle each day and scheduled future appointments for the rest. At NTIHC, the trained peer counselors determined that they could only counsel 20 young people each day, and so they accepted only the first 20 that came for VCT services each morning. Since then, however, they have added more counselors and now provide VCT to more youth.

Eventually the outreach activities had to be discontinued to reduce the demand created by their promotional messages - a finding that highlights an important conclusion of the study: There is immense unmet demand for VCT among youth, and VCT centers that set out to attract youth need to plan accordingly, which includes having adequate space and trained counselors. The study also shows that special training of providers, improved services, lowered fees, and additional testing sites attract more youth to testing.

For more information, contact Milka Juma at (mjuma@pcnairobi.org) or go to www.popcouncil. org/horizons/ for a summary of this research. $\mathbb{X}$

${ }^{1}$ Horizons Program, Kenya Project Partners, and Uganda Project Partners. "HIV voluntary counseling and testing among youth: Results from an exploratory study in Nairobi, Kenya, and Kampala and Masaka, Uganda," Horizons Baseline Report. Washington, DC: Population Council.

\section{WASHINGTON, DC}

New resource provides ethical guidance for collecting information from children

A $s$ the demand grows for support services for children and adolescents affected by HIV/AIDS, so does the need for data to assess whether these programs are truly making a difference. Investigators and program managers gathering this information face new and difficult ethical issues. Are children who lack adult protection and guidance capable of understanding the potential consequences of participating in a study - in other words, can they give truly informed consent? Are survey questions about the death of parents or other sensitive subjects likely 
to cause anxiety or even emotional damage? Could visits from a researcher "brand" a child as HIV-affected and deepen the stigma he or she may already experience?

Few resources currently exist to help program managers and evaluators deal with the difficult and potentially harmful situations that may arise when working with children affected by HIV/AIDS. At the request of the U.S. Agency for International Development (USAID), a steering group was formed composed of representatives of the Horizons Program, Family Health International's IMPACT Program, UNICEF, and USAID to develop a practical guidance resource for those who work with young people in international settings. Recognizing that methods for working with adults cannot simply be transferred to young people, the new resource identifies challenges that confront program implementers and investigators who work with children and adolescents and proposes practical approaches to dealing with them. It also provides case studies that highlight the roles of interviewers, program managers, data analysts, and others in ensuring that child-related activities are not harmful or unethical.

"Because of the power imbalance between adult investigators and child informants, gathering information from children requires additional precautions to protect their confidentiality, privacy, and emotional well-being," said Katie Schenk of Horizons/Population Council, who coordinated the development of the resource. "Involving everyone who participates in programming and research is critical to ensuring that these precautions are met."

As groundwork for the development of the publication, an expert consultation meeting took place in 2003. The gathering included researchers and service providers with expertise in psychology, child development, ethics, pediatrics, sociology, anthropology, and social work. This broad mix of perspectives and expertise led to a fruitful exchange about both ethical concerns and the practical issues involved in implementing effective standards.

Meeting participants discussed the ethical responsibilities of working with children affected by AIDS and other difficult situations, who often face poverty, stigma, or abuse. Participants agreed that program managers and researchers must take steps in advance to make sure that referral systems to local services are in place to help children in these situations, and that both parents or guardians and children know that abuse will be reported to the appropriate authorities.

Among other topics raised by meeting participants and covered by the publication are gaining meaningful informed consent for children and creating opportunities for children to participate as advocates on their own behalf in study design, instrument development, and results interpretation.

Ethical Approaches to Gathering Information from Children and Adolescents in International Settings will soon be available on the web at www.popcouncil.org/horizons. $\mathbb{X}$

\section{HgrizonsReport}

The Horizons Report is a biannual newsletter produced by the Horizons Program, which is dedicated to global operations research on HIV/AIDS prevention, care, and support.

Published in June 2005

Editorial Staff: Alison Clarke, Sherry Hutchinson, and Ellen Weiss

Special thanks to Margo Young, ICRW for her help with this issue.

For more information on the Horizons Program, or to be included on our mailing list, please contact us at:

Horizons Program

Communications Unit

4301 Connecticut Ave. NW, Suite 280

Washington, DC 20008 USA

Tel: 202-237-9400

Fax: 202-237-8410

E-mail: horizons@pcdc.org

www.popcouncil.org/horizons
Horizons Program, Population Council offices SOUTH AFRICA

P.O. Box 411744

Craighall 2024, Johannesburg

Tel: 27-11-325-0518

csearle@pcjoburg.org.za

KENYA

General Accident House

Ralph Bunche Road

P.O. Box 17643

Nairobi 00500

Tel: 254-2-713-480/1/2/3

kkiragu@pcnairobi.org

INDIA

53 Lodi Estate, 3rd Floor

New Delhi 110003

Tel: 91-11-469-9747/8

horizons@pcindia.com

THAILAND

P.O. Box 138, Pratunam

Bangkok 10409

Tel: 66-2-251-4766/7066

pcbkk@popcouncil.th.com

ISSN: 1539-5103
(1) Population Council

The Population Council is an international, nonprofit, nongovernmental institution that seeks to improve the well-being and reproductive health of current and future generations around the world and to help achieve a humane, equitable, and sustainable balance between people and resources. The Council conducts biomedical, social science, and public health research and helps build research capacities in developing countries. Established in 1952 , the Council is governed by an international board of trustees.

Copyright (C) 2005 The Population Council Inc.

This publication was made possible through support provided by the President's Emergency Plan for AIDS Relief through the Office of HIV/AIDS, U.S Agency for International Development (USAID), under the terms of HRN-A00-97-00012-00. The opinions expressed herein are those of the authors and do not necessarily reflect the views of USAID.

This document may be reproduced in whole or in part without permission of the Population Council provided full source citation is given and the reproduction is not for commercial purposes. 